\section{A study of factors that influence the number of visits following traumatic dental injuries}

\author{
J. Keasberry, ${ }^{1}$ T. Munyombwe, ${ }^{2}$ M. Duggal ${ }^{3}$ and P. F. Day*4
}

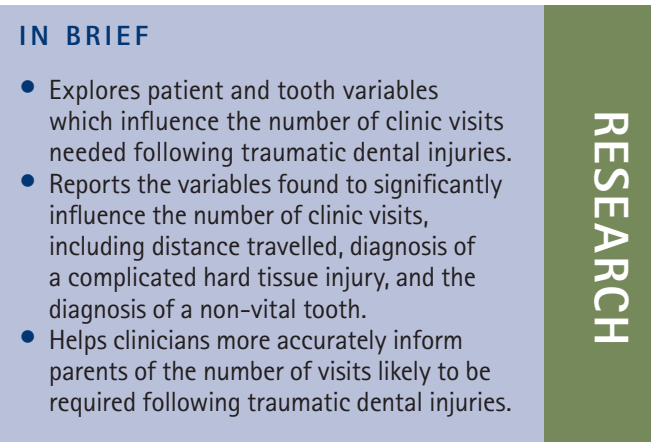

\begin{abstract}
Objective To investigate in children the factors that influence the number of visits per tooth following traumatic dental injuries (TDI) to the permanent dentition. Method A retrospective convenient sample of 100 children who had been treated for TDI at Leeds Dental Institute was identified. A multilevel negative binomial regression model was developed to identify factors influencing the number of visits per tooth. Data including age, gender, postcode, number of visits, treatment provided, number of teeth injured, type of periodontal and hard tissue diagnoses, healing modality, root maturity, pulp and tooth survival, and any history of previous or subsequent trauma to same tooth were analysed using SPSS 18.0 and MLWIN. Results 186 teeth were affected by trauma in 100 patients. Median total number of visits per tooth was six visits with a range of 1-22 visits. The factors that were found to influence number of visits included: distance travelled, hard tissue diagnosis, periodontal injury diagnosis and pulp survival $(P<0.05)$. A mile increase in distance travelled from home to clinic led to a $1.2 \%$ reduction in the number of visits per month $(-0.012 ; \mathrm{SE} 0.005)$, a diagnosis of a severe hard tissue injury was associated with $44 \%$ increase (0.362; SE 0.105) compared to no hard tissue injury, a diagnosis of a complicated periodontal injury compared to no periodontal injury was associated with a 30\% increase (0.260; SE 0.124), a diagnosis of a uncomplicated periodontal injury compared to no periodontal injury was associated with a 31\% increase $(0.271 ;$ SE 0.124$)$ and a diagnosis and treatment for a non-vital tooth in comparison to a vital tooth led to a $26 \%$ increase $(0.230 ; \mathrm{SE} 0.080)$ in the number of visits. There was a significant variation in the number of treatment visits at patient level (0.260; SE 0.048). Conclusion Complicated hard tissue injuries, complicated and uncomplicated periodontal injuries, diagnosis and treatment for pulp necrosis and the distance between clinic and patient's home all significantly influenced the number of visits needed to treat TDI.
\end{abstract}

\section{INTRODUCTION}

Trauma to the permanent dentition is common. ${ }^{1}$ In the United Kingdom, the number of children experiencing trauma to the permanent dentition increases with age from 5\% at eight years old to 13\% at age fifteen years old. ${ }^{2}$ Despite occupying only $1 \%$ of the body surface, oral injuries were the third most common site of traumatic accidents in childhood. ${ }^{3}$ Traumatic dental injuries (TDI) are of special interest to

'Specialist, Paediatric Dental Unit, RIPAS Hospital, Brunei Darussalam; ${ }^{2}$ Biostatistian, Centre for Epidemiology Et Biostatistics, LIGHT, University of Leeds; ${ }^{3}$ Professor of Paediatric Dentistry, ${ }^{4}$ Associate Professor of Paediatric Dentistry, Leeds Dental Institute and Bradford Salaried Dental Service, University of Leeds, Clarendon Way, Leeds, LS2 9LU.

*Correspondence to: Peter Day

Email:p.f.day@leeds.ac.uk; Tel: 01133436139

Online article number E28

Refereed Paper - accepted 23 April 2013

DOI: $10.1038 /$ sj.bdj.2013.532

${ }^{\oplus}$ British Dental Journal 2013; 214: E28 paediatric dentists as over three quarters of these injuries occur in childhood. ${ }^{3}$

Unsurprisingly, the anterior teeth are the most frequently injured teeth especially the maxillary central incisors. ${ }^{4}$ These injuries not only affect oral health and appearance but facial aesthetics as well. Research has shown that during childhood and adolescence, injuries can impact on oral health related quality of life especially if they are untreated. ${ }^{5}$ Porritt et al. ${ }^{6}$ identified that functional limitations and school-related activities were most likely domains to be affected and these impacts continued even after they had received treatment. Thelen et al. ${ }^{7}$ reported that children with untreated injuries had a reduced oral health related quality of life and were 'less likely to smile and show their teeth without embarrassment' when compared to children with no dental trauma. The consequences do not stop with the child affected but can influence how other children perceive them and adults interact with them. ${ }^{8-10}$

Barriers to treating TDI as reported by dentists include: inadequate financial remuneration; the feeling that time spent on trauma was excessive; the irregular frequency and thus unfamiliarity with managing complicated injuries. ${ }^{11,12}$ Consequently in the UK many children are referred for their trauma treatment to specialist paediatric centres. The impact of this care on children and parents can be considered both in time and expense. The cost following avulsion and replantation was investigated by Nyugen et al. ${ }^{13}$ and they reported an average financial burden of CAD $\$ 1,465$ (£933, based on an exchange rate of $£ 1$ to $\operatorname{CAD} \$ 1.57$, Feb 2013) in the first year alone. Ninety percent of children and $86 \%$ of parents reported time lost from school and work. Wong and Kolokotsa ${ }^{14}$ calculated that the average cost of treating 
a TDI per patient was £856 and identified that main cost was for travelling and time away from work for parents and school for children. Borum and Andreasen ${ }^{4}$ estimated the cost of treating a complicated TDI ranged from US $\$ 926$ to US $\$ 1,490$ (£588 to £947, based on an exchange rate of $€ 1$ to US\$1.57, Feb 2013) in Denmark. The number of appointments needed to provide treatment and follow up review appointments was reported as an average of 9.2 visits for uncomplicated TDI and 16.4 visits for complicated TDI. ${ }^{15}$

While treatment guidelines prescribed treatment interventions required for different TDI and advise clinicians on the frequency and duration of follow-up visits, to date there has been very limited research to identify what factors influence the number of clinic visits needed. Where these factors can be identified this information can inform children, parents and clinicians planning trauma services. Therefore, the aim of this study was to identify what factors influenced the number of visits a patient needed following a TDI to their permanent dentition.

\section{MATERIALS AND METHOD}

For children to be included in this study, they had to fulfil the following inclusion criteria:

- To be seen on the Leeds Dental Institute (LDI) trauma clinic from April 2003 to April 2007

- To have attended the clinic for at least one visit during this period

- To have suffered a TDI to at least one of the permanent teeth

- To be less than 17-years-old at their first appointment

- To be in good health. Patients with a medical condition such as epilepsy, cerebral palsy, learning difficulties, hearing impairment, attention deficit hyperactivity disorder or with autism were excluded

- To complete treatment at the LDI of the most severely affected tooth, making that tooth functional, infection-free and with an acceptable appearance to children and parents.

The following data were collected using a proforma: age at time of injury, gender, postcode, date of trauma, number of teeth injured, diagnosis of hard tissue and periodontal tissue at time of injury, ${ }^{16}$ stage of root development, any history of previous or subsequent trauma to the same tooth, the number of treatment visits per child and per tooth, and the number of review visits per child and per tooth. A treatment visit was defined as a visit where active treatment was provided to the traumatised tooth. A review visit was defined as a visit where the injured tooth was examined with special tests results recorded and/or radiographs taken. The total number of visits per tooth was summated from the number of treatment visits and the number of review visits. Other information gleaned from the clinical records was the subsequent diagnosis of periodontal healing; pulp survival and tooth survival.

The severity of hard tissue and periodontal injuries were classified into mild, severe and no injury. ${ }^{17}$ Uncomplicated hard tissue injuries were classified as those not involving the pulp or root for example, infraction, enamel, or enamel-dentine fracture. Complicated hard tissue injuries include fractures involving the pulp, cementum or root. Uncomplicated periodontal injuries were defined as those with no displacement of the tooth namely concussion and subluxation. Complicated periodontal injuries included lateral luxation, extrusion, intrusion and avulsion.

To determine root development, radiographs were assessed at the initial visit. Root maturity was classified as divergent, convergent, parallel or closed. ${ }^{18}$ Periodontal healing was defined as healing with no pathology, uncertain healing at the time of final visit or unfavourable healing including replacement and infection-related resorption. Pulp survival was classified as vital, non-vital or uncertain pulpal healing (for example, where there were clinical and radiographic concerns of the tooth's vitality but the pulp had not been extirpated). Tooth survival was classified according to tooth present, absent or where only the root was present.

Various types of dental treatment were provided and these included: replanting, splinting, suturing, root canal treatment, crown build-up, denture, decoronation, orthodontic extrusion, bleaching, veneer, resin-bonded bridges and autotransplantation. Treatment was deemed completed when the most severely injured tooth was functional, had an acceptable appearance
Table 1 The root maturity of the 186 teeth seen radiographically at the initial visit

\begin{tabular}{l|l|l}
\multicolumn{2}{l|}{ Root maturity } & $\begin{array}{l}\text { Number } \\
\text { of teeth }\end{array}$ \\
\hline Opened apex & Divergent & 20 \\
\hline & Parallel & 34 \\
\hline Closed apex & Convergent & 52 \\
\hline Teeth unaccounted - avulsed & 76 \\
\hline
\end{tabular}

or had been replaced with a denture, a bridge or an autotransplanted tooth; with the patient discharged or placed on longterm review. If the child was treated with autotransplantation, the transplanted tooth was considered a new tooth and subsequent treatment visits were not included in the analysis.

\section{Statistical analysis}

Data were modelled using multilevel Poisson and multilevel negative binomial regression models. The outcome variable for the multilevel models was number of visits per tooth. Since the outcome variable was count data, the first choice for modelling was to use the Poisson distribution. Treatment visits for multiple injured teeth in the same person are not independent and thus ignoring the dependency in the data will result in the underestimation of standard errors for regression coefficients. If standard errors of regression coefficients are underestimated, it might be inferred that there is a significant difference when the difference is due to chance (Type I error). Multilevel models were used to account for the clustering in the data. Multilevel models have previously been used for dental research. ${ }^{19}$ The model used consisted of two levels (tooth within patients). Two level multilevel Poisson and negative binomial models were fitted, with patients as second level and tooth as first level. The predictors were selected, based on clinical knowledge and these included: age at the time of the accident, gender, distance travelled in miles, diagnosis of hard tissue injuries, diagnosis of periodontal tissue injuries, root development, periodontal healing, pulp survival, tooth survival and previous or subsequent traumatic injuries. Since the patients had different observation periods, the duration of treatment in months was included as the offset for the model. 
Table 2 Types of hard tissue and periodontal tissue injuries diagnosed at the initial visit to Leeds Dental Institute by the individual tooth $(n=186)$

\begin{tabular}{|c|c|c|c|c|c|c|c|c|c|}
\hline \multicolumn{5}{|c|}{ Uncomplicated injuries } & \multicolumn{5}{|c|}{ Complicated injuries } \\
\hline & & None & Concussion & Subluxation & $\begin{array}{l}\text { Lateral } \\
\text { luxation }\end{array}$ & Extrusion & Intrusion & Avulsion & Total \\
\hline & None & 0 & 19 & 19 & 5 & 1 & 2 & 18 & 64 \\
\hline \multirow{3}{*}{$\begin{array}{l}\text { Uncomplicated } \\
\text { injuries }\end{array}$} & Infraction & 3 & 1 & 0 & 0 & 0 & 0 & 0 & 4 \\
\hline & Enamel $^{*}$ & 9 & 1 & 0 & 1 & 0 & 0 & 0 & 11 \\
\hline & $E / d^{*}$ & 48 & 2 & 2 & 0 & 3 & 5 & 3 & 63 \\
\hline \multirow{4}{*}{$\begin{array}{l}\text { Complicated } \\
\text { injuries }\end{array}$} & $E / d / p^{\#}$ & 22 & 2 & 1 & 0 & 0 & 0 & 0 & 25 \\
\hline & $E / d / c^{*}$ & 1 & 0 & 0 & 0 & 0 & 0 & 0 & 1 \\
\hline & $E / d / c / p^{*}$ & 5 & 0 & 0 & 0 & 0 & 0 & 0 & 5 \\
\hline & Root $^{*}$ & 5 & 1 & 2 & 2 & 1 & 0 & 2 & 13 \\
\hline Total & & 93 & 26 & 24 & 8 & 5 & 7 & 23 & 186 \\
\hline
\end{tabular}

The Poisson model assumes that the mean is equal to the variance. Where the variance is greater this indicates overdispersion in the data. Ignoring this over dispersion will result in incorrect standard errors. Instead a negative binomial model was used to model any overdispersion in the data. A multilevel Poisson model was fitted first and then compared with a multilevel negative binomial model. The regression coefficients for the two models were very similar but the standard errors of the negative binomial model were larger. Thus the multilevel negative binomial model was chosen.

No priori sample size was conducted for the multilevel modelling, as no estimates of intracluster correlation were available to determine the appropriate sample size. The aim of this study was to determine regression coefficients, variance components and standard errors with accuracy. Simulation studies by Mass and $\mathrm{Hox}^{20}$ have shown that having less than 100 second level units will result in biased second level variances therefore in this study we had 186 teeth from 100 patients.

The following assumptions were made for the modelling purpose as a result of the missing data encountered in Tables 1 and 4 discussed later in the text. For the four teeth that were not replanted, root maturity was estimated, based on their age and the other injured teeth for which data were available. Periodontal healing and pulpal survival was not available for nine teeth. In five cases where

Table 3 Treatment provided for 186 teeth from 100 children following TDI injuries to the permanent dentition and seen at Leeds Dental Institute

\begin{tabular}{|c|c|}
\hline Treatment provided & Number of teeth \\
\hline No treatment provided & 50 \\
\hline Replanted/repositioned & $\begin{array}{l}3 \\
\text { Two teeth were retained in the mouth } \\
\text { One tooth was eventually lost and replaced with denture then } \\
\text { later resin retained bridge }\end{array}$ \\
\hline Splinting & 28 \\
\hline Resplinting & $\begin{array}{l}7 \text { teeth resplinting once } \\
1 \text { tooth resplinting twice }\end{array}$ \\
\hline Root canal treatment & 76 \\
\hline Root canal retreatment & $\begin{array}{l}6 \text { teeth twice } \\
1 \text { tooth thrice }\end{array}$ \\
\hline Crown build-up & 97 \\
\hline Crown build-up retreatment & $\begin{array}{l}17 \text { teeth needed crown build-up twice } \\
10 \text { teeth thrice } \\
3 \text { teeth four times } \\
1 \text { tooth five times } \\
2 \text { teeth six times }\end{array}$ \\
\hline Extractions & 13 \\
\hline Denture fitted & 16 \\
\hline Denture remake or denture fracture & $\begin{array}{l}4 \text { dentures twice } \\
5 \text { dentures replaced thrice } \\
1 \text { denture replaced four times }\end{array}$ \\
\hline Orthodontic extrusion & 3 \\
\hline Bleaching & $\begin{array}{l}2 \\
\text { Both teeth were bleached a second time }\end{array}$ \\
\hline Resin bonded bridge & 10 \\
\hline Premolar transplant & 4 \\
\hline
\end{tabular}

the tooth was extracted, or not replanted before attendance at the specialist centre, four teeth were avulsed and one tooth was intruded, periodontal healing was recorded as resorption and pulpal healing as non-vital. In four further cases where the teeth were lost, one root fracture, one crown root fracture and two cases of enamel dentine fractures that were injured on three separate occasions, the periodontal healing was recorded as healing and the pulpal healing as non-vital. 


\section{RESULTS}

Nine hundred and sixty-one patients were identified from the day sheet records of LDI trauma clinic. One hundred and eighty seven patients' records were available to analyse. From this initial number, 64 did not meet the inclusion criteria and a further 23 did not complete their treatment at LDI. The sample therefore compromised 100 patients' clinical records with 186 injured teeth. The median age of the sample was 9-years-old with a range between 5 and 16-years-old. Fifty-five children were male. On a patient basis, the median total number of visits was nine, with a range of 1-28 visits. The median distance from the patient's home address to LDI was 8.8 miles with a range of 1-67 miles.

Each tooth was analysed as an individual entity with the number of visits calculated per tooth. The median total number of visits per tooth was six, with a range of 1-22 visits. The median number of treatment visits per tooth was two, with a range from zero, where no treatment was required, to 14 visits. The median number of review visits per tooth was three, with a range from $0-10$ visits. The root maturity demonstrated an even distribution across the four different developmental stages ${ }^{18}$, as shown in Table 1. A random ten percent sample of radiographs were re-examined at baseline and midway through the study to assess the intra-examiner (J. K.) reproducibility. Excellent agreement was achieved with kappa scores of 0.81 and 0.89 .

Table 2 shows the frequency of different hard tissue and periodontal tissue injuries, with enamel dentine fractures being the most common injury. The type and frequency of different treatments provided for each tooth is shown in Table 3 and composite crown build-ups were the most common treatment provided, followed by root canal treatment. The type of periodontal healing diagnosed for each tooth, together with the pulp and tooth survival, is reported in Table 4. This sample comprises of $41 \%$ of teeth that were diagnosed as non-vital and received root canal treatment.

Table 5 shows the results from the multivariable multilevel Poisson and multilevel negative binomial models. The regression coefficients for both models were almost the same. The negative binomial, however, had larger standard errors compared to

Table 4 The outcome of 186 teeth following TDI at their final visit to Leeds Dental Institute. For further details regarding the missing data please see the method section

\begin{tabular}{l|l|l|l|l}
\hline Dental condition & \multicolumn{4}{l|}{ Number of teeth } \\
\hline Periodontal healing at final visit & $\begin{array}{l}\text { Healing } \\
155\end{array}$ & $\begin{array}{l}\text { Uncertain healing } \\
3\end{array}$ & $\begin{array}{l}\text { Resorption } \\
19\end{array}$ & $\begin{array}{l}\text { Missing Data } \\
9\end{array}$ \\
\hline Pulp survival at final visit & $\begin{array}{l}\text { Vital } \\
98\end{array}$ & $\begin{array}{l}\text { Uncertain healing } \\
3\end{array}$ & Non-vital 76 & $\begin{array}{l}\text { Missing Data } \\
9\end{array}$ \\
\hline Tooth survival at final visit & $\begin{array}{l}\text { Present } \\
162\end{array}$ & $\begin{array}{l}\text { Root present } \\
2\end{array}$ & $\begin{array}{l}\text { Absent } \\
22\end{array}$ & - \\
\hline $\begin{array}{l}\text { Previous or subsequent trauma } \\
\text { episodes to same tooth }\end{array}$ & $\begin{array}{l}\text { Repeat } \\
46\end{array}$ & $\begin{array}{l}\text { No previous trauma } \\
140\end{array}$ & - & - \\
\hline
\end{tabular}

the Poisson model. Therefore, the results discussed in this study are based on the multilevel negative binomial model.

The independent predictors of the number of visits per month were: distance travelled from home to clinic, diagnosis of complicated hard tissue, diagnosis of a complicated or uncomplicated periodontal injury, and the diagnosis and treatment of non-vital tooth. A mile increase in distance travelled from home to clinic led to a 1.2\% decrease $(-0.120$; SE 0.005$)$ per month, a diagnosis of a severe hard tissue injury was associated with 44\% increase (0.362; SE 0.105) compared to no hard tissue injury, a diagnosis of a complicated periodontal injury compared to no periodontal injury was associated with a 30\% increase (0.260; SE 0.124), a diagnosis of a uncomplicated periodontal injury compared to no periodontal injury was associated with a $31 \%$ increase $(0.271$; SE 0.124$)$ and a diagnosis and treatment for a nonvital tooth in comparison to a vital tooth led to a $26 \%$ increase (0.230; SE 0.080) in the number of visits. There was significant variation in number of visits at patient level (0.260; SE 0.048). The effect of age, total number of teeth injured, gender, root development, periodontal healing, tooth survival, previous or subsequent traumatic injuries were not statistically significant.

\section{DISCUSSION}

\section{Methodology}

To date there has been one prospective study undertaken to study the impact of TDI with respect to the number of visits ${ }^{15}$ and costs ${ }^{21}$ associated to the child and their family. Other studies from Sweden, ${ }^{22,23}$ Canada, ${ }^{13}$ Jordan, ${ }^{24}$ Denmark ${ }^{4}$ and the $\mathrm{UK}^{14}$ have been retrospective in their design. This study has used a similar retrospective design. This methodology has a number of limitations, which include: the need for detailed and legible records, the need for missing data to be imputed, and the limitations of the sample selected. Despite a large number of children who attended one or more appointments at the trauma clinic at LDI in the time frame, only 187 clinical records were available in the medical records department and had not been archived off site. A benefit of this sample was that all patients were treated under the clinical expertise of a consultant in paediatric dentistry (M. S. D.) with considerable expertise in TDI. The treatment provided would have followed the relevant guidelines for the time frame from International Association of Dental Traumatology ${ }^{25,26}$ and British Society of Paediatric Dentistry. ${ }^{27,28}$

The lead author (J. K.) collected all the data, with quality assurance of data collection provided by two other authors (P. D. and M. S. D.). The classification of root maturity was checked against expert agreement (P. D., M. S. D.) and demonstrated good intra-examiner reproducibility. The statistical analysis allowed full evaluation of the data while respecting the data hierarchy as shown in Figure 1, for example, teeth were nested in children where multiple teeth were affected. The multilevel Poisson and negative binomial models ${ }^{29}$ approach permitted teeth to be analysed individually and allowed the impact of patient factors and tooth factors to be analysed in a longitudinal study with patients seen for a variable lengths of time. It allowed for a) the determination of important predictors of the number of visits per tooth and the extent of their influence, b) the study of relationship between the number of visits per tooth and each of the factors (predictors) while at the same time controlling the effect of other factors, and c) the prediction of the value of the number of visits per tooth from the factors (predictors) using the model. 
Table 5 The multilevel Poisson and multilevel negative binomial model for 186 teeth with TDI nested in 100 children, investigating the variables which influence the number of visits needed. The coefficient estimates and standard error (in brackets) are given for both models

\begin{tabular}{|c|c|c|c|c|c|c|c|c|}
\hline & Variable & & $\begin{array}{l}\text { Model 1: } \\
\text { null model } \\
\text { Poisson }\end{array}$ & $\begin{array}{l}\text { Model 2: } \\
\text { model with } \\
\text { covariates - } \\
\text { Poisson } \\
\end{array}$ & $\begin{array}{l}\text { Model 3: } \\
\text { (null model) } \\
\text { negative } \\
\text { binomial } \\
\end{array}$ & $\begin{array}{l}\text { Model 4: } \\
\text { model with } \\
\text { covariates - } \\
\text { negative binomial }\end{array}$ & $\begin{array}{l}\text { Exponential } \\
\text { coefficient } \\
\text { for model } 4\end{array}$ & $\begin{array}{l}\text { Size of effect } \\
(\%) \text { on num- } \\
\text { ber of visits }\end{array}$ \\
\hline \multirow{14}{*}{$\begin{array}{l}\text { Fixed } \\
\text { effects }\end{array}$} & Constant & & $-1.533(0.059)$ & $-2.262(0.322)$ & $-1.534(0.059)$ & $-2.267(0.308)$ & & \\
\hline & Age & & & $0.026(0.030)$ & & $0.033(0.029)$ & 1.033 & \\
\hline & Gender & Female vs. male & & $-0.067(0.118)$ & & $-0.094(0.118)$ & 0.910 & \\
\hline & Distance & & & $-0.012(0.005)^{* *}$ & & $-.012(0.005)^{* *}$ & 0.988 & 1.2 \\
\hline & $\begin{array}{l}\text { Number of teeth } \\
\text { injured }\end{array}$ & & & $0.077(0.062)$ & & $0.067(0.062)$ & 1.069 & \\
\hline & \multirow{2}{*}{ Hard tissue } & $\begin{array}{l}\text { No injury vs. } \\
\text { uncomplicated }\end{array}$ & & $0.123(0.122)$ & & $0.176(0.092)$ & 1.192 & \\
\hline & & $\begin{array}{l}\text { No injury vs. } \\
\text { complicated }\end{array}$ & & $0.366(0.133)^{* *}$ & & $0.362(0.105)^{* *}$ & 1.436 & 44 \\
\hline & \multirow{2}{*}{$\begin{array}{l}\text { Periodontal injury } \\
\text { diagnosis }\end{array}$} & $\begin{array}{l}\text { Uncomplicated } \\
\text { vs. no injury }\end{array}$ & & $0.281(0.140)$ & & $0.271(0.113)^{* *}$ & 1.311 & 31 \\
\hline & & $\begin{array}{l}\text { Uncomplicated } \\
\text { vs. complicated }\end{array}$ & & $0.325(0.148)^{* *}$ & & $0.260(0.124)^{* *}$ & 1.296 & 30 \\
\hline & $\begin{array}{l}\text { Root } \\
\text { development }\end{array}$ & $\begin{array}{l}\text { Mature vs. } \\
\text { immature }\end{array}$ & & $-0.038(0.131)$ & & $-0.123(0.116)$ & 0.884 & \\
\hline & $\begin{array}{l}\text { Periodontal } \\
\text { healing }\end{array}$ & $\begin{array}{l}\text { Healing vs. } \\
\text { resorption }\end{array}$ & & $-0.093(0.187)$ & & $-0.061(0.152)$ & 0.941 & \\
\hline & Pulp survival & Non-vital vs. vital & & $0.183(0.100)$ & & $0.230(0.080)^{* *}$ & 1.259 & 26 \\
\hline & Tooth survival & Present vs. absent & & $0.071(0.181)$ & & $0.113(0.144)$ & 1.119 & \\
\hline & $\begin{array}{l}\text { Previous or sub- } \\
\text { sequent trauma }\end{array}$ & No vs. yes & & $0.022(0.106)$ & & $-0.053(0.088)$ & 0.948 & \\
\hline $\begin{array}{l}\text { Random } \\
\text { effects }\end{array}$ & & & $0.222(0.047)$ & $0.175(0.040)$ & $0.218(0.049)$ & $0.217(0.041)$ & & \\
\hline
\end{tabular}

The statistical model was developed to identify the factors associated with the number of tooth visits. No priori sample size calculation was conducted, as there were no estimates for sample size calculation. The sample was moderate in size and therefore this may have led to other important predictors not reaching significance. For example number of teeth injured, which is examined later in the discussion, has been shown to be a significant factor in other studies ${ }^{15,23}$ but not in this sample. This study has generated estimates that can be used for sample size determination in future prospective studies. Adding covariates to the null model, did not reduce the variability significantly at tooth level, it may be that other variables not examined in this study may have influenced the number of visits required.

\section{Sample selected}

As shown in Table 2, the sample by the nature of being seen at a specialist centre was skewed towards a complex injury profile in comparison to injuries presenting in general dental practice. ${ }^{11}$ The age and gender distribution were within normal ranges for a paediatric TDI sample. ${ }^{1}$ Injuries classified by either their hard tissue or periodontal injury diagnosis as complicated ${ }^{17}$ accounted for $46 \%$ of the injured teeth. Only $16 \%$ of injuries were combination injuries with both a periodontal and hard tissue injury diagnosed. This is less than the proportion of one third of injuries reported by a Danish specialist centre but may be partially explained by the delayed presentation of trauma seen in many paediatric centres in the UK. ${ }^{30}$ This delay has the consequences that uncomplicated periodontal injuries frequently have healed by the time of the initial consultation at LDI.

Crown build-up was the most prescribed treatment, as shown in Table 3. Seventeen teeth needed crown build-up twice and 10 teeth thrice. Robertson et al. ${ }^{31}$ reported that over a period of 17 years, 19\% of restorations following crown fractures were changed ten times and 25\% of restorations were deemed unsatisfactory at the final assessment. Despite these outcomes, provision of composite crown build-ups to restore crowns fractures is important as demonstrated by studies showing a poorer oral health related quality of life where no restoration had been provided. 5,7,10

Approximately a quarter of the teeth, as shown in Table 4, had suffered either previous or subsequent trauma, which supports a similar prevalence figures from other literature. ${ }^{1}$ The percentage of non-vital teeth, $43 \%$, explains the high number of root canal treatments recorded in Table 3. The prevalence of $16 \%$ of the sample with avulsion and intrusion combined with some complex hard tissue injuries explains the percentage of missing teeth, $11 \%$, and those with unfavourable root resorption, $11 \%$. It is commonly reported that teeth with such complex periodontal injuries frequently suffer such outcomes. ${ }^{32,33}$ 
Furthermore within the trauma clinic at LDI early identification of failing teeth is encouraged and interdisciplinary planning undertaken for the management of failing and missing traumatised teeth. ${ }^{34}$

\section{Impact on children and their parents}

This study identified that $76 \%$ of children completed their treatment within four years with patients needing a median of nine visits. To date the impact of the number of visits following TDIs on the child and parent has only been reported in one other UK based study. ${ }^{14}$ Wong and Kolokosta $^{14}$ found a median of eight visits were needed, while a Swedish study ${ }^{22}$ found that nine visits were needed. A Canadian study ${ }^{13}$ reported the number of visits in the first year alone following avulsion injury and found a mean of six visits, including 1.2 emergency and 4.8 follow up visits. UK specialist paediatric centres rarely provide acute care for TDI and therefore this study, together with that of Wong and Kolokosta, ${ }^{14}$ may underestimate the total number of visits required to manage TDI. ${ }^{35}$

The median distance travelled was 8.8 miles with 59\% of the sample living within an 11 mile radius of the LDI. This shows that the majority of patients live close to the specialist centre. How TDI are managed for children who live a greater distance from the specialist centres is unknown, especially those with complex injuries. Glendor highlighted the significant component of the indirect costs and estimated that 30\% of indirect time was taken up with transportation when attending clinic visits. ${ }^{15}$ The multilevel model identified a significant influence of patient level variables on the number of visits. The most important of these patient factors was distance between the specialist clinic and the home address. This variable accounted for a $1.2 \%$ reduction in the number of visits for every mile increase in distance between clinic and home address. Clinicians are often aware when patients have travelled a significant distance and may try to maximise the amount of treatment they provide per visit or this factor may concentrate the clinician's decision making on the frequency of review appointments needed. The number of teeth injured was not found to be significant in its influence

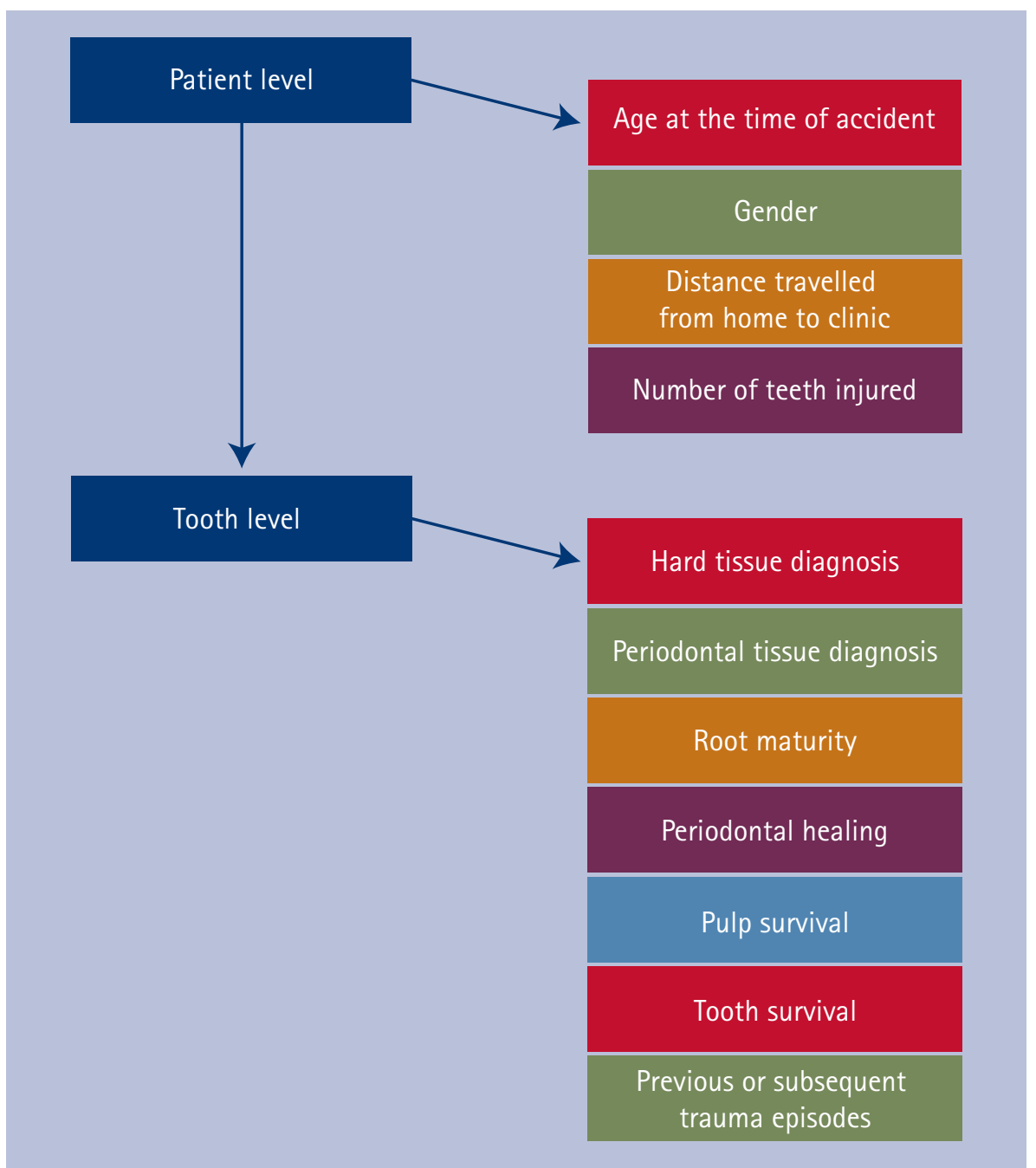

Fig. 1 Shows the variables at patient and tooth levels for the multilevel Poisson and negative Binominal modelling

on the number of visits per tooth which differs from other literature. ${ }^{15,23}$ This may relate to the sample as only $36 \%$ of patients had three or more teeth injured.

The cost of providing care following TDI can be estimated in a similar way as that described by Wong and Kolokosta. ${ }^{14}$ The average cost of an outpatient dental hospital visit was $€ 65$, based on Dental SIFT in 1999-2000. ${ }^{36}$ This is then multiplied by the median number of visits (nine visits). The cost, assuming loss of work for the parent involved, can be calculated by using the median gross weekly earning of a full time employee in April 2010 of £499. ${ }^{37}$ Therefore, a half day taken off work would equate to $£ 49.90$ loss of income/productivity. Therefore this cost is $£ 449$. Finally, the costs of transport assuming a car journey at 40 pence per mile can be calculated. The median distance travel between the home address and the LDI was 8.8 miles. The travel costs could be estimated at $£ 63$. The average cost of treatment following this very simple estimation is $£ 1,097$. This estimate lacks the detail and complexity carried out by Glendor et al. ${ }^{21}$ and neither does it take into account the future costs for on-going and potentially more definitive dental care in adulthood or the child's loss of opportunity from missing time from school. What is obvious is that the socio-economic costs following TDI are substantial and require detailed long-term studies to fully quantify them.

\section{Factors that influence number of visits}

Tooth variables that had a significant impact on the number of visits were periodontal diagnosis, hard tissue injury diagnosis, and the diagnosis and treatment for pulp necrosis. The strongest influence, 44\% increase in number of visits, was the diagnosis of a complicated hard tissue injury in comparison to no hard tissue injury. A smaller, 30\% increase in number of visits, but significant variable was complicated 
periodontal injuries in comparison to no injury. The diagnosis of complicated TDI on the number of visits has been found by several other studies. ${ }^{4,14,15,22,23}$ and therefore the influences of these factors agrees with the current literature. Glendor estimated a 2.5 times increase in time taken to treat complicated injuries ${ }^{15}$ and a tripling in costs involved. ${ }^{21}$ Borssen estimated that complicated injuries could explain a third of the variation in the number of visits. ${ }^{23}$

An interesting finding from this study was the significant effect of an uncomplicated periodontal injury compared to no periodontal injury on the number of visits. Moreover the size of effect, 31\% increase in the number of visits, was of a comparable nature to that of a complicated periodontal injury. This is a novel finding and not previously reported in the literature. A possible explanation is the finding of increased pulp necrosis when there is concomitant uncomplicated periodontal and hard tissue diagnoses. ${ }^{38,39}$ For uncomplicated hard tissue injuries in comparison to no hard tissue injury this variable came close to significance, thereby supporting this possible mechanism of increasing the number of visits needed following TDI. Some caution is needed with this explanation in that there were only six teeth with concomitant uncomplicated hard tissue and periodontal injuries.

The final tooth-related factor was the hard tissue outcome, with teeth requiring root canal treatment increasing the number of visits by $26 \%$. Except in cases of elective pulp extirpation following certain hopeless TDI, where pulp necrosis is guaranteed; almost all endodontics is undertaken on infected root canals warranting a number of visits of disinfection before obturation. Interesting root immaturity showed an influence on the number of visits with a $12 \%$ reduction in visits for mature tooth but this did not reach a significant level. This limited difference may be explained with the increasing use of mineral trioxide aggregate (MTA) in the study period rather than undertaking apexification with calcium hydroxide. This change in protocol may have reduced the influence of root maturity ${ }^{40}$ on the number of visits needed for root canal treatment. Al-Jundi ${ }^{24}$ reported the need for 17 visits for the provision of apexification compared to ten visits for root canal treatment while Pradhan et al. ${ }^{40}$ found that for immature teeth the time to barrier formation reduced from seven months with calcium hydroxide compared to three months for MTA. A current guideline does not specify which treatment option for non vital immature teeth should be chosen, ${ }^{41}$ although the number of visits needed to complete treatment will be a strong influence in the choice of clinicians and parents. In contrast, however, the use of new regenerative techniques will increase the number of clinic visits required, owing to the greater frequency of clinical and radiographic monitoring needed. ${ }^{41}$

\section{CONCLUSION}

This study, only the second in the United Kingdom, has investigated which factors influence the number of visits children require following TDI. The use of the multilevel negative binomial model has identified the following significant factors at patient and tooth level: the diagnosis of a complicated hard tissue injury, the diagnosis of a complicated or uncomplicated periodontal injury, the diagnosis and treatment for pulp necrosis and the distance between clinic and patient's home. By identifying these significant factors, this study will help clinicians inform parents of how many visits they and their child are likely to require following different TDI to their permanent dentition.

1. Glendor U. Epidemiology of traumatic dental injuries - a 12 year review of the literature. Dent Traumatol 2008; 24: 603-611.

2. Chadwick B L, White D A, Morris A J, Evans D, Pitts $\mathrm{N} \mathrm{B}$. Non-carious tooth conditions in children in the UK, 2003. Br Dent J 2006; 200: 379-384.

3. Eilert-Petersson E, Andersson L, Sorensen S. Traumatic oral vs non oral injuries. Swed Dent $J$ 1997; 21: 55-68.

4. Borum M K, Andreasen J 0. Therapeutic and economic implications of traumatic dental injuries in Denmark: an estimate based on 7549 patients treated at a major trauma centre. Int J Paediatr Dent 2001; 11: 249-258.

5. Cortes M I, Marcenes W, Sheiham A. Impact of traumatic injuries to the permanent teeth on the oral health-related quality of life in 12-14-year-old children. Community Dent Oral Epidemiol 2002; 30: 193-198.

6. Porritt J M, Rodd H D, Baker S R. Quality of life impacts following childhood dento-alveolar trauma. Dent Traumatol 2011; 27: 2-9.

7. Thelen D S, Trovik T A, Bardsen A. Impact of traumatic dental injuries with unmet treatment need on daily life among Albanian adolescents: a casecontrol study. Dent Traumatol 2011; 27: 88-94.

8. Rodd H D, Barker C, Baker S R, Marshman Z Robinson $P$ G. Social judgements made by children in relation to visible incisor trauma. Dent Traumatol 2010; 26: 2-8.

9. Vlok J L, Worthington E M, Hindson J A, Davidson $L E$, Thomson W M, Drummond B K. Young people's perceptions of photographs of dental trauma. Dent Traumatol 2011; 27: 109-112.
10. Fakhruddin K S, Lawrence H P, Kenny D J, Locker D. Impact of treated and untreated dental injuries on the quality of life of Ontario school children. Dent Traumatol 2008; 24: 309-313.

11. Jackson N G, Waterhouse P J, Maguire A. Management of dental trauma in primary care: a postal survey of general dental practitioners. Br Dent J 2005; 198: 293-297.

12. Hamilton F A, Hill F J, Holloway P J. An investigation of dento-alveolar trauma and its treatment in an adolescent population. Part 2: dentists' knowledge of management methods and their perceptions of barriers to providing care. Br Dent J 1997; 182: 129-133.

13. Nguyen P M T, Kenny D J, Barrett E J. Socioeconomic burden of permanent incisor replantation on children and parents. Dent Traumato/ 2004; 20: 123-133.

14. Wong F S, Kolokotsa K. The cost of treating children and adolescents with injuries to their permanent incisors at a dental hospital in the United Kingdom. Dent Traumatol 2004; 20: 327-333.

15. Glendor U, Halling A, Bodin L et al. Direct and indirect time spent on care of dental trauma: a 2-year prospective study of children and adolescents. Endod Dent Traumatol 2000; 16: 16-23.

16. Glendor U, Marcenes W, Andreasen J 0. Classification, Epidemiology and Etiology. In Andreasen J 0, Andreasen F M, Andersson L, (eds). Textbook and colour atlas of traumatic injuries to the teeth. pp 217-254. 4th ed. Copenhagen: Blackwell Munksgaard, 2007.

17. Glendor U, Halling A, Andersson L, Eilert-Petersson E. Incidence of traumatic tooth injuries in children and adolescents in the county of Vastmanland, Sweden. Swed Dent J 1996; 20: 15-28.

18. Welbury R R, Kinirons M J, Day P F, Humphreys K, Gregg T A. Outcomes for root-fractured permanent incisors: a retrospective study. Paediatr Dent 2002; 24: 98-102.

19. Gilthorpe M S, Maddick I H, Petrie A. Introduction to multilevel modelling in dental research. Community Dent Health 2000; 17: 222-226.

20. Maas C J M, Hox J J. Sufficient sample sizes for multilevel modeling. Methodo/ 2005; 1: 86-92.

21. Glendor U, Jonsson D, Halling A, Lindqvist K. Direct and indirect costs of dental trauma in Sweden: a 2-year prospective study of children and adolescents. Community Dent Oral Epidemiol 2001; 29: 150-160.

22. Glendor U, Halling A, Andersson L, Andreasen J O, Klitz I. Type of treatment and estimation of time spent on dental trauma-a longitudinal and retrospective study. Swed Dent J 1998; 22: 47-60.

23. Borssen E, Kallestal C, Holm A K. Treatment time of traumatic dental injuries in a cohort of 16 -year-olds in northern Sweden. Acta Odontol Scand 2002; 60: 265-270.

24. Al-Jundi $\mathrm{S} \mathrm{H}$. Type of treatment, prognosis, and estimation of time spent to manage dental trauma in late presentation cases at a dental teaching hospital: a longitudinal and retrospective study. Dent Traumatol 2004; 20: 1-5.

25. Flores M T, Andreasen J O, Bakland L K et al. Guidelines for the evaluation and management of traumatic dental injuries. Den/ Traumatol 2001; 17: 145-148.

26. Flores M T, Andreasen J O, Bakland L K et al. Guidelines for the evaluation and management of traumatic dental injuries. Dent Traumatol 2001; 17: 193-198.

27. Gregg T A, Boyd D H. UK National Clinical Guidelines in Paediatric Dentistry. Treatment of avulsed permanent teeth in children. Int J Paediatr Dent 1998; 8: 75-81.

28. Kinirons M J. Treatment of traumatically intruded permanent incisor teeth in children. UK National Clinical Guidelines in Paediatric Dentistry. Int J Paediatr Dent 1998; 8: 165-168.

29. Muller H P. Dealing with hierarchical data in periodontal research. Clin Oral Investig 2009 13: $273-278$.

30. Zaitoun H, North S, Lee S, Albadri S, McDonnell S T, Rodd H D. Initial management of paediatric dento-alveolar trauma in the permanent dentition: a multi-centre evaluation. Br Dent J 2010; 208: E11 
discussion 254-255.

31. Robertson A, Robertson S, Noren J G. A retrospective evaluation of traumatized permanent tooth. Int J Paediatr Dent 1997; 7: 217-226

32. Andreasen J O, Borum M K, Jacobsen $H$ L, Andreasen F M. Replantation of 400 avulsed permanent incisors 4. Factors related to periodontal ligament healing. Dent Traumatol 1995; 11: 76-89.

33. Tsilingaridis $\mathrm{G}$, Malmgren $\mathrm{B}$, Andreasen J 0 Malmgren 0 . Intrusive luxation of 60 permanent incisors: a retrospective study of treatment and outcome. Dental Traumatol 2012; 28: 416-422.

34. Day P F, Kindelan S A, Spencer J, Kindelan J, Duggal M S. Dental trauma: part 2. Managing poor prognosis anterior teeth- treatment options for the subsequent space in a growing patient. J Orthod 2008; 35: 143-155.
35. Day P F, Gregg T A, Ashley P et al. Periodontal healing following avulsion and replantation of teeth: a multi-centre randomized controlled trial to compare two root canal medicaments. Dental Traumatol 2012; 28: 55-64.

36. Department of Health. Dental SIFT (service increment for teaching) accountability report. London: HMSO, 2000.

37. Office for National Statistics. Annual survey and hours and earnings 2010. Available online at: http:// www.ons.gov.uk/ons/rel/ashe/annual-survey-ofhours-and-earnings/2010-revised-results/index. html (accessed May 2013).

38. Lauridsen E, Hermann N V, Gerds T A, Ahrensburg $S S$, Kreiborg $S$, Andreasen J 0. Combination injuries 1. The risk of pulp necrosis in permanent teeth with concussion injuries and concomitant crown fractures. Dent Traumato/ 2012; 28: 364-370

39. Lauridsen E, Hermann N V, Gerds T A, Ahrensburg SS, Kreiborg S, Andreasen J O. Combination injuries 2. The risk of pulp necrosis in permanent teeth with subluxation injuries and concomitant crown fractures. Dent Traumato/ 2012; 28: $371-378$.

40. Pradhan D P, Chawla H S, Gauba K, Goyal A. Comparative evaluation of endodontic management of teeth with unformed apices with minera trioxide aggregate and calcium hydroxide. J Dent Child 2006; 73: 79-85.

41. Diangelis A J, Andreasen J O, Ebeleseder K A et al. International Association of Dental Traumatology guidelines for the management of traumatic dental injuries: 1. Fractures and luxations of permanent teeth. Dent Traumato/ 2012; 28: 2-12. 